\title{
Post-radiation fibrosarcoma of the breast
}

\author{
M. S. Lemson, H. J. Mud, A. J. Wijnmaalen* and R. W. M. Giard ${ }^{\dagger}$ \\ Departments of Surgery and Pathology, St Clara Hospital, *Department of Radiation Oncology, Dr Daniel Den Hoed \\ Cancer Center, Rotterdam, The Netherlands
}

$S U M M A R Y$. We report the first case of fibrosarcoma of stromal breast tissue occurring 11 years after breast-conserving therapy for breast cancer. A review of six cases of stromal malignant fibrous histiocytoma is presented, developing between 5 years and 11 years after breast radiation. Since all cases developed in the area of boost irradiation, abandoning the booster dose might reduce the incidence of secondary sarcomas. Treatment of radiation-induced sarcoma should be surgical, with wide excisional margins. A lifelong follow-up is recommended for patients treated with breast-conserving therapy for primary cancer.

\section{INTRODUCTION}

Post-radiation sarcoma is a rare but well-recognized late effect of cancer therapy. Sarcomas following therapeutic radiation after mastectomy for breast cancer were first described by Warren \& Sommer in $1936^{1}$ and since then many cases were reported. ${ }^{2-4}$ After the introduction of breast-conserving therapy for breast cancer several cases of angiosarcoma $a^{5,6}$ and malignant fibrous histiocytoma $a^{7-11}$ of the radiated breast were described. We report the first case of post-radiation stromal fibrosarcoma occurring 11 years after breast-conserving therapy for primary breast cancer.

\section{CASE REPORT}

In July 1981, a 45-year-old woman presented with a palpable $1.5 \mathrm{~cm}$ mass in the upper outer quadrant of the left breast. IIistopathological examination of the lumpectomy specimen showed a moderately well-differentiated adenocarcinoma of the breast. The margins of resection were clear of tumour. Subsequently, the patient underwent an axillary lymph node dissection. No metastases were found. Postoperatively radiation therapy was given to the breast. A total dose of 45 Gy was given in 25 fractions over 36 days through two tangential fields with a photon energy of $6 \mathrm{MV}$. The pri-

Address correspondence to: H. J. Mud, Department of Surgery, St Clara Hospital, Olympiaweg 350, 3078 HT Rotterdam, The Netherlands mary site received a booster dose of 20 Gy given in 10 fractions using $13 \mathrm{MeV}$ electrons with a total treatment time of 18 days. Eighteen months after completing the radiation therapy, the breast felt firm on palpation, indicating moderate fibrosis. This remained unchanged during follow-up. There were no changes of skin appearance and the cosmetic result was excellent.

In May 1992, almost 11 years after treatment for breast cancer, the patient returned prior to her yearly check-up because she noticed a palpable lump at the site of the primary tumour. Aspiration cytology of the lesion showed no malignant cells. However, mammography had obviously changed showing a dense area at the site of the primary tumour, which was marked by clips at the operation in 1981 (Fig. 1). It was decided to perform an excisional biopsy June 1992, as recurrence of breast cancer was suspected. At histopathological examination the tumour was composed of atypical spindle cells. No other cell types (such as multinucleated giant cells) were seen, so it was classified as a fibrosarcoma grade II (Fig. 2). The margins of resection were clear of tumour. As computer tomography of thorax and abdomen showed no metastases, a more radical excision was advised. The paticnt underwent a left mastectomy on 25 June 1992 with a partial resection of the thoracic wall. In cooperation with the reconstructive surgeon the defect was closed with a soft tissue Goretex-patch $\circledR^{*}$ (W. L. Gore \& Associates BV, Hertogenbosch) which was covered by a transposition graft of the latissimus dorsi muscle and a split skin graft. No residual tumour was found on histopathological examination. Postoperatively the patient's recovery was uneventful and she is alive and well 42 months after the operation. 


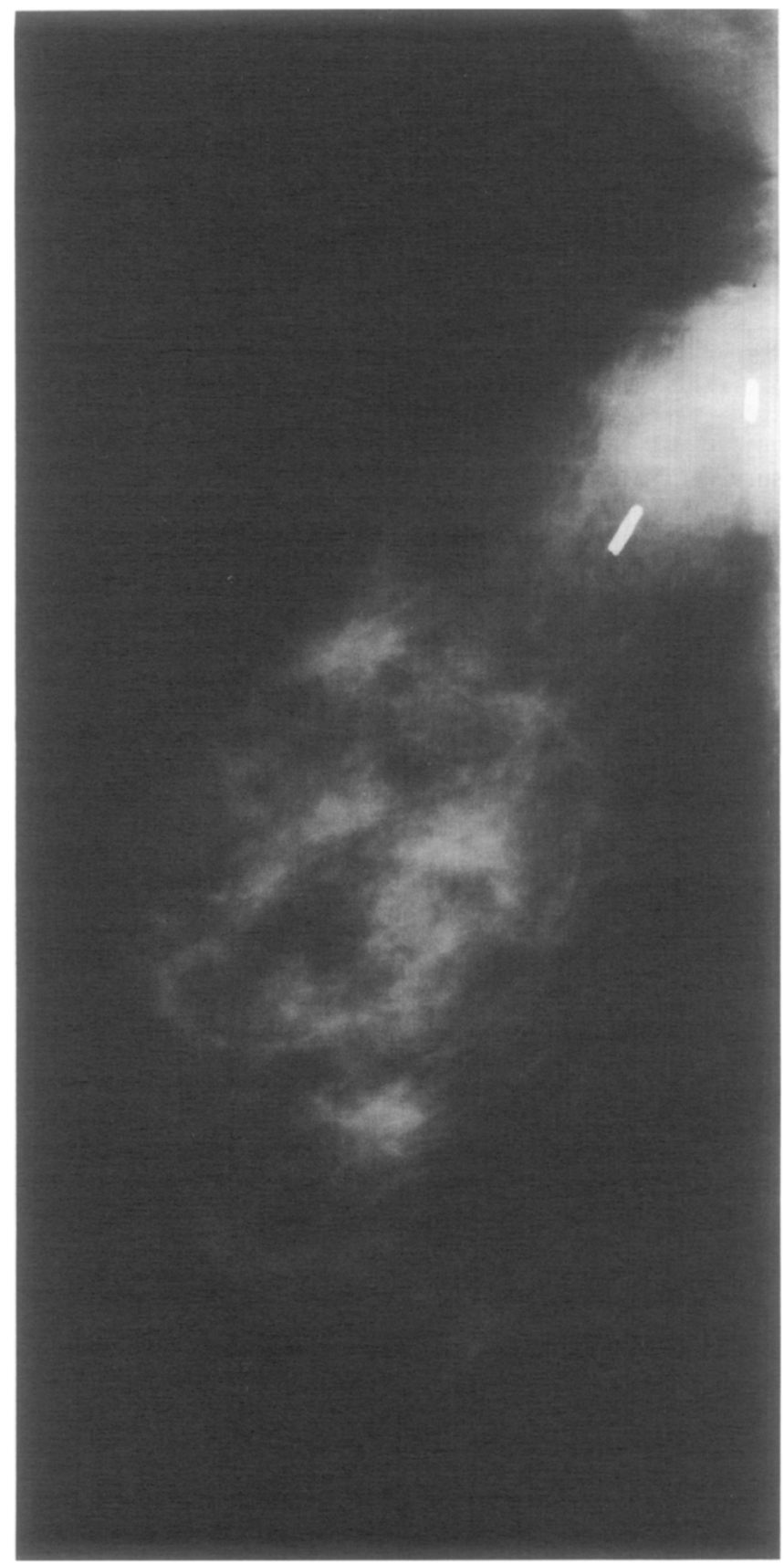

Fig. 1 Mammography of May 1992 showing a dense area of $1.5 \mathrm{~cm}$ with irregular margins at the site of the haemoclips placed during the primary operation in 1981.

\section{DISCUSSION}

In women treated for breast cancer, $40-50 \%$ of the secondary malignancies are carcinoma of the other breast. ${ }^{8,9.12} \mathrm{Kurtz}^{9}$ and $\mathrm{Basco}^{13}$ could not provide proof for an increased risk of radiation-induced carcinoma in the contralateral breast since contralateral secondary carcinoma is also seen in nonirradiated women. Other second malignancies reported after

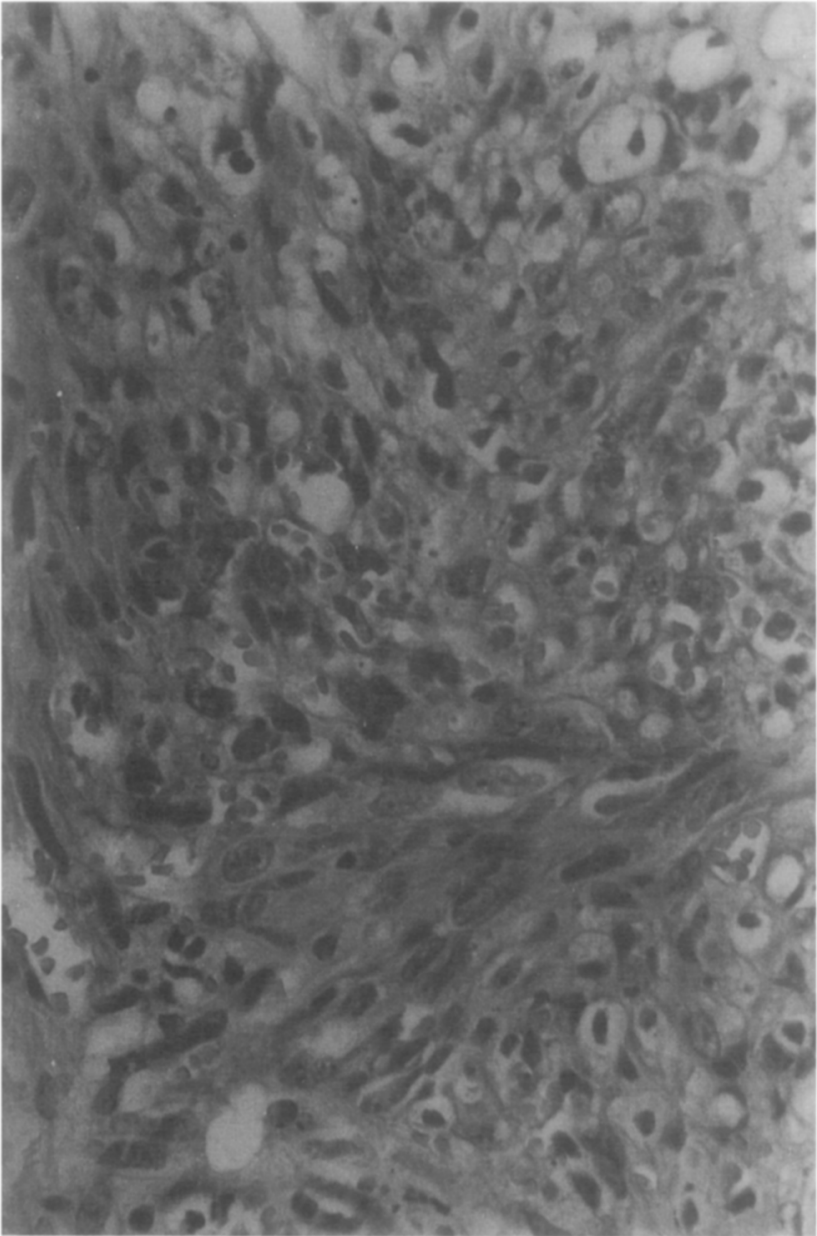

Fig. 2 Fibrosarcoma consisting of atypical spindle cells showing variation in size and shape. An arrangement in fascicle is discernible $(\mathrm{H} \& \mathrm{E} \times 270)$.

radiotherapy for breast cancer are carcinoma of the lung and oesophagus, sarcoma of the bone, soft tissue sarcoma and acute non-lymphatic leukemia. ${ }^{8,12,14}$ In 1948 Cahan defined four criteria for a radiation induced tumour:

1. The tumour must have a different histology from the primary lesion

2. The tumour must arise in a previously irradiated area

3. A significant latent period (more than 5 years) must have elapsed after irradiation

4. The sarcomatous nature of the post-radiation lesion must be histologically proven. ${ }^{15}$

The overall incidence of sarcomas that occur following radiation therapy for any disease is $0.2-0.3 \%$ at 10 years. ${ }^{2,9,12,16-18}$ There is no difference in the incidence of post-radiation sarcoma between orthovoltage or megavoltage treatment although there seems to be a shorter latency period for bone sarcomas in megavoltage as compared to orthovoltage radiation ( 7.4 years vs 15.9 years).$^{19,20}$ 
Table All reported cases of malignant fibrous histiosarcoma and a case of fibrosarcoma after breast-cunserving therapy for breast cancer

\begin{tabular}{lclclc}
\hline Author & Total dose (Gy) & Sarcoma & Latency (years) & Treatment of sarcoma & Follow-up \\
\hline Souba $^{10}$ & 50 & MFH & 9 & Surgery & 10 months, alive \\
Delouche $^{8}$ & 60 & MFH & 11 & Surgery \& chemotherapy & 4 years, alive \\
Kurtz $^{11}$ & $>60$ & MFH & 10.5 & Surgery \& chemotherapy & 4 years, alive \\
Kurtz $^{9}$ & 70 & MFH & 5 & NS & NS, dead \\
Kurtz $^{9}$ & 80 & MFH & 5.5 & NS & NS, dead \\
Turner $^{7}$ & 48 & MFH & 5 & Surgery \& chemotherapy & 1 year, alive \\
Present report & 65 & FS & 11 & Surgery & 42 months, alive \\
\hline
\end{tabular}

MFH = malignant fibrous histiocytoma; FS = fibrosarcoma; NS = not stated.

In 1936 Warren \& Sommer reported the first case of fibrosarcoma occurring at the left side of the chest 24 years after mastectomy and radiation treatment for cancer of the breast. ${ }^{1}$ Since then many such cases were reported..$^{2-4,10,17,19-21}$ The mean latency period for radiation induced sarcomas after mastectomy is 11 years. ${ }^{17,22}$ However, they have been reported as late as 45 years after radiotherapy. ${ }^{23}$

With the introduction of breast-conserving therapy, the risk for secondary sarcoma developed in the remaining tissue of the breast. $^{8}$ In 1987 Body et al reported the first angiosarcoma of the skin of the breast occurring 5 years after breast-conserving therapy for breast cancer. ${ }^{5}$ Since then, to our knowledge, only 15 cases have been reported. ${ }^{6}$ Secondary sarcoma of the breast parenchyma occurring after breast-conserving therapy was first described in 1986. ${ }^{24}$ This concerned a malignant fibrous histiocytoma 2 years and 2 months after wide excision of an infiltrating duct cell carcinoma followed by breast irradiation. This time interval is rather short for a post-radiation sarcoma to be induced. Only six similar cases were described, details of which are listed in Table. ${ }^{7-11}$ All occurred within the area of excision, which was boosted following whole breast irradiation and at least 5 years after breast-conserving therapy for breast cancer. We present the first fibrosarcoma, also occurring within the boosted area 11 years after breast-conserving therapy. In animal studies a parabolic dose-response curve was described for tumour induction by irradiation with a maximum dose beyond which tumour induction decreases. ${ }^{24}$ As the described tumours all occured in the area of boost irradiation, this maximum is probably not reached with a dose of $65 \mathrm{~Gy}$. Meta-analysis ${ }^{25}$ of the reviewed articles showed an incidence of post-radiation sarcoma after mastectomy between 0.0007 and $0.003 .2,3,4,17$ After breastconserving therapy the incidence was $0.0002-0.006^{8,9,11}$

Primary sarcoma of the breast accounts for less than $1 \%$ of all primary breast malignancies. ${ }^{18}$ The mortality at 5 years is $64 \%$ but does not increase thereafter. The mainstay of treatment is to gain local control through mastectomy with excision of the pectoral muscle. Radiation and chemotherapy neither show a reduction in the rate of local recurrence or metastatic disease, nor do they improve the overall survival. ${ }^{18}$ Treatment of secondary sarcomas should be surgical and equally aggressive, as these tumours are also likely to have a high tendency to recur. ${ }^{19,22}$ Despite treatment, survival for all radiation induced sarcomas is $35 \%$ at 2 years compared to $60 \%$ for all primary sarcomas. ${ }^{19}$ Secondary sarcoma of the breast after breast-conserving therapy for primary cancer is a rare but serious problem. Every palpable lump or change on the mammography must be considered to be a recurrence of the primary disease or a secondary sarcoma until proven otherwise. Since the secondary stromal sarcomas described all occurred in the area of boost irradiation, this seems to be an area of increased risk. The occurrence of secondary cancer may decrease if the boost irradiation can be abandoned safely, that is, without increasing the risk on local recurrence. As secondary sarcomas have been reported up to 45 years after radiation, a life-long surveillance is advised in all patients treated with radiation therapy.

\section{References}

1. Warren S, Sommer G N. Fibrosarcoma of the soft parts with special reference to recurrence and metastasis. Arch Surg 1936; 33: 425-450.

2. Hatfield P M, Schulz M D. Post-irradiation sarcoma, including five cases after X-ray therapy of breast carcinoma. Radiology 1970; 96: 593-602.

3. Hatlinghus S, Rode L, Christensen I, Vaage S. Sarcoma following irradiation for breast cancer. Report of three unusual cases including one malignant mesenchymoma of bone. Act Rad Oncol 1986; 25: 239-242.

4. Ferguson D J, Sutton H G, Dawson P J. Late effects of adjuvant radiotherapy for breast cancer. Cancer 1984; 54: 2319-2323.

5. Body G, Sauvanaet E, Calais G, Fignon A, Fetissof F, Lansac J. Angiosarcome cutané du sein après adénocarcinome mammaire opéré irradié. J Gynecol Obstet Biol Reprod 1987; 16: 479-483.

6. Wijnmaalen A J, Ooijen B van, Geel A N van, Henzen-Logmans S C, Treurniet-Donker A D. Angiosarcoma of the breast following lumpectomy, axillary lymph-node dissection and radiotherapy for primary breast cancer: three case reports and a review of the literature. Int J Rad Oncol Biol Phys 1993; 26: 135-139.

7. Turner W H, Greenall M J. Sarcoma induced by radiotherapy after breast conservation surgery. Br J Surg 1991; 78: 1317-181.

8. Delouche G, Bachelot F, Premont M, Kurtz J M. Conservation treatment of early breast cancer: long-term results and complications. Int J Rad Oncol Biol Phys 1987; 13: 29-34.

9. Kurtz J M, Amalric R, Brandone H, Ayme Y, Spitalier J. 
Contralateral breast cancer and other second malignancies in patients treated by breast-conserving therapy with radiation. Int J Rad Oncol Biol Phys 1988; 15: 277-284.

10. Souba W W, McKenna R J, Meis J, Benjamin R, Raymond K, Mountain C F. Radiation-induced sarcomas of the chest wall. Cancer 1986; 57: 610-615.

11. Kurtz J M, Amalric R, Delouche G, Pierquin B, Roth J, Spitalier J. The second 10 years: long-term risks of breast conservation in early breast cancer. Int J Rad Oncol Biol Phys 1987; 13: 1327-1332.

12. Harvey E B, Brinton L A. Second cancer following cancer of the breast in Connecticut, 1935-1982. Natl Cancer Inst Monogr 1985; 68: 99-112.

13. Basco V E, Coldman A J, Elwood J M, Young M E J. Radiation dose and second breast cancer. Br J Cancer 1985; 52: 319-325.

14. Ewertz M, Mouridsen H T. Second cancer following cancer of the female breast in Denmark, 1943-1980. Natl Cancer Inst Monogr 1985; 68: 325-329.

15. Cahan W G, Woodward H Q, Higinbothan N L, Steward S W, Coley B L. Sarcoma arising in irradiated bone: report of 11 cases. Cancer $1948 ; 1: 3-29$.

16. Kim J H, Chu F C, Woodard H Q, Melamed M R, Huvos A G, Cantin J. Radiation-induced soft-tissue and bone sarcoma. Radiology 1978; 129: 501-508.

17. Taghian A, De Vathaire F, Terrier $P$ et al. Long-term risk of sarcoma following radiation treatment for breast cancer. Int J Rad Oncol Biol Phys 1991; 21: 361-367.

18. Pollard S G, Marks P V, Temple L N, Thompson H H. Breast sarcoma. A clinicopathologic review of 25 cases. Cancer 1990; 66: 941-944.

19. Laskin W B, Silverman T A, Enzinger F M. Postradiation soft tissue sarcomas. An analysis of 53 cases. Cancer 1988; 62: 2330-2340.

20. Wiklund T A, Blomqvist C P, Räty J, Elomaa I, Rissanen P. Postirradiation sarcoma. Analysis of a nationwide cancer registry material. Cancer 1991; 68: 524-531.

21. Adam Y G, Reif $R$. Radiation-induced fibrosarcoma following treatment for breast cancer. Surgery $1977 ; 81: 421-425$.

22. Amendola B E, Amendola M A, McClatchey K D, Miller C H. Radiation-associated sarcoma: a review of 23 patients with postirradiation sarcoma over a 50-year period. Am J Clin Oncol $1989 ; 12: 411-415$.

23. Davidson T, Westbury G, Harmer C L. Radiation-induced soft-tissue sarcoma. Br J Surg 1986; 73: 308-309.

24. Luzzatto R, Grossmann S, Scholl J G, Recktenvald M. Postradiation pleiomorphic malignant fibrous histiocytoma of the breast. Acta Cyt 1986; 30: 48-50.

25. Hall E J. Radiation carcinogenesis. Radiobiology for the radiologist, 4th edn. Philadelphia: JB Lippincott Company, 1984; 323-334.

26. DerSimonian R, Laird N. Meta-analysis in clinical trials. Controlled Clinical Trials 1986; $7: 177-188$. 